\title{
Efeitos da ação dos ácidos graxos na pele sadia por biometria cutânea*
}

\section{Action effects of fatty acids in healthy skin by skin biometry*}

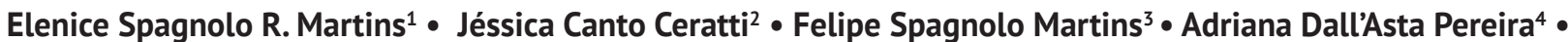 \\ Ana Paula Tasquetto Silva ${ }^{5}$ - Carina Rodrigues Boeck ${ }^{6}$ • Solange Cristina da Silva ${ }^{7}$
}

\begin{abstract}
RESUMO
Neste estudo objetivou-se investigar o efeito da aplicação tópica dos óleos de chia, girassol e canola, por meio de biometria cutânea, mensurando a hidratação, Perda Transepidérmica de Água (PTEA), oleosidade e eritema. Tratase de uma pesquisa experimental, com amostra de 44 voluntários, que utilizaram os respectivos óleos no cotovelo esquerdo por 28 dias e foram avaliados nos dias 0, 7,14, 21 e 28. Observou-se que todos os óleos estudados aumentaram a hidratação do cotovelo, porém, o óleo de chia apresentou o melhor resultado. Na avaliação da PTEA o óleo de canola apresentou o menor índice, porém, todos os óleos testados aumentaram a oleosidade do cotovelo, em especial o óleo de girassol. 0 óleo que teve menor reação tecidual foi o óleo de chia, quando comparado aos outros óleos testados. Logo, conclui-se que este estudo comprova a efetividade do óleo de chia na hidratação e diminuição de eritema da pele, prevenindo dano tissular e proporcionando efeitos benéficos na pele.
\end{abstract}

Palavras-chave: Enfermagem; Ácidos Graxos Essenciais; Biometria Cutânea.

\begin{abstract}
The present study aims to investigate the effects of the topical application of chia, sunflower and canola oils by cutaneous biometry, measuring hydration, Transepidermal Water Loss (TEWL), oiliness and erythema. This is an experimental study, with a sample of 44 volunteers, who used the respective oils in the left elbow for 28 days, and so on days 0,7 th, 14th, 21th and 28th. It was observed that all the oils studied increased hydration of the elbow, however, the chia oil showed the best result. In the evaluation of the PTEA, the canola oil had the lowest index, but all the oils tested increased the oiliness of the elbow, especially the sunflower oil. The oil that had the lowest tissue reaction was chia oil, when compared to the other oils tested. Therefore, it is concluded that this study proves the effectiveness of chia oil on the hydration and reduction of erythema of the skin, preventing tissue damage and providing beneficial effects on the skin.
\end{abstract}

Keywords: Nursing; Essential Fatty Acids; Skin Biometry.

Os autores declaram que não há qualquer conflito de interesse.

*Artigo derivado de Trabalho Final de Graduação II,“Efeitos da ação dos ácidos graxos na pele sadia por biometria cutânea”, autoria de Elenice Spagnolo R Martins e Jéssica do Canto Ceratti, apresentado no Centro Universitário Franciscano- Santa Maria-RS, em dezembro de 2016.

${ }^{1}$ Enfermeira. Doutoranda do programa de pós graduação em Nanociências - Docente do curso de Enfermagem do Centro Universitário Franciscano- Santa Maria-RSelenice.s.martins@gmail.com.

${ }^{2}$ Enfermeira, graduada pelo Centro Universitário Franciscano- Santa Maria-RS- jessicaceratti_12@hotmail.com.

${ }^{3}$ Acadêmico de Medicina do Centro Universitário Franciscano Santa Maria- RS - fe_551@hotmail.com.

${ }^{4}$ Enfermeira. Doutora em Ciências- Universidade Federal de São Paulo- professor Adjunto do Centro Universitário Franciscano Santa Maria-RS adrianadap@terra.com.br

${ }^{5}$ Farmacêutica. Doutora em Nanociências- Centro Universitário Franciscano- Santa Maria-RS ana.paula.ts@hotmail.com.

${ }^{6}$ Química. Doutora em Ciências Biológicas: Bioquímica- Universidade Federal do Rio Grande do Sul.- professor Adjunto do Centro Universitário Franciscano Santa Maria- RS cariboeck@hotmail.com

${ }^{7}$ Farmacêutica. Doutora em Química- Universidade Federal de Santa Maria - professor Adjunto do Centro Universitário Franciscano Santa Maria-RS. solangecr13@gmail.com. 


\section{INTRODUÇÃO}

Uma das formas de manter a integridade da pele se faz por meio da aplicação de Ácidos Graxos Essenciais (AGE), sendo estes, um dos recursos mais usados para prevenir a desidratação da pele e auxiliar no tratamento de feridas. Os AGE favorecem a manutenção da integridade da pele por conter propriedades hidratantes e evitar a Perda Transepidérmica de Água (PTEA). Há relatos de que os AGE têm ação bactericida devido ao seu baixo $\mathrm{pH}$, o que interfere na permeabilidade da membrana celular da bactéria, auxiliando assim na barreira cutânea contra agentes nocivos ${ }^{1}$.

Atualmente existem diversos tipos de ácidos graxos, porém com relação ao tratamento de feridas, o ácido linoléico (C18: 2- $\omega-6)$ e o ácido linolênico (C18: 3- $\omega$ 3), são os mais importantes pois não são sintetizados pelos mamíferos, por não possuírem a enzima delta 9-dessaturase, por isso então são chamados de AGE².

$\mathrm{O}$ ácido linoléico foi testado no tratamento de úlceras venosas avaliando a sua capacidade de estimular o tecido de granulação e consequentemente acelerar a cicatrização. Úlceras venosas tratadas com ácido linoléico apresentaram um resultado estatisticamente significativo, no desenvolvimento do tecido de granulação e cicatrização destas lesões num período de 7 a 28 dias de tratamento ${ }^{3}$.

Já o ácido linolênico, favorece a manutenção da integridade da barreira de permeabilidade epidérmica acelerando os processos cicatriciais. Estas substâncias agem como moduladoras da membrana celular protegendo a lesão; agindo como protetor da pele contra agentes químicos e enzimáticos, protegendo-a da umidade da diurese e das fezes, agindo e protegendo a pele contra infecções por Staphylococus Aureus, regulando a permeabilidade da barreira de água da pele $e^{4-5}$.

Muitos produtos compostos de AGE são ricos em ácido linoléico e ácido linolênico e são utilizados para auxiliar na manutenção da pele. Estes podem ser encontrados em óleos como os de chia, girassol e canola ${ }^{5}$.

O óleo de chia contém ácidos graxos poli-insaturados, e tem como seus principais componentes o ácido linoléico (17-26\%) e linolênico (50-57\%), sendo também fonte de antioxidantes naturais disponíveis como matéria prima para seu uso em: alimentos funcionais, nutricêuticos e suplementos dietéticos ${ }^{6}$.

Estudo com óleo de chia foi realizado para avaliar o efeito tópico do óleo da semente de chia na pele de cinco pacientes saudáveis com prurido e cinco pacientes com insuficiência renal terminal ou com diabetes, também com prurido. Após oito semanas, todos referiram melhora dos sintomas e não tiveram efeitos adversos. Deste modo, os autores concluem que o óleo de chia pode ser usado como um hidratante no tratamento de pacientes que apresentem prurido ${ }^{7}$.

O girassol (Helianthus Annus) é uma planta originária do México, cresce na Europa central e na Rússia meridional, necessitando de muito sol e umidade. Suas sementes têm em seu óleo o ácido oleico, e uma grande quantidade de ácidos graxos, especialmente o ácido linoléico ${ }^{8}$.

$\mathrm{O}$ óleo de girassol é rico em vitamina $\mathrm{E}$, que favorece consequentemente a hidratação da pele mantendo acelerado o processo de envelhecimento. Sabe-se que as deficiências de vitaminas $A, C$ e $E$ podem contribuir em possíveis casos de lesões por pressão, já que estas vitaminas desempenham um importante papel na síntese do colágeno, imunidade e integridade epitelial ${ }^{8-9}$.

O óleo de girassol foi avaliado, usado topicamente, em feridas na região torácica de carneiros, próxima à escápula. As lesões do lado direito foram tratadas com óleo de girassol, com alta concentração de ácido linoléico (65\%) e as lesões do lado esquerdo (controle) tratadas com vaselina esterilizada, as quais foram mantidas ocluídas. As feridas tratadas com óleo de girassol apresentaram um aumento da velocidade cicatricial, acelerando a formação de tecido de granulação, em relação ao grupo controle ${ }^{8}$

As origens da canola estão ligadas ao cultivo das sementes oleaginosas conhecidas como sementes de colza. A história mostra que as civilizações antigas da Ásia e Europa usavam o azeite de colza em suas lâmpadas. Mais tarde, ele também foi utilizado em alimentos, como azeite para cozinhar. Este óleo contém ômega 3 e 6, que atuam no controle da inflamação e na reparação tecidual. Quando aplicado à pele, possui função semelhante aos demais óleos como a produção de substâncias pró inflamatórias e a neutralização de lesões através do $\mathrm{pH}^{10}$.

O óleo de canola, por conter grande quantidade de ácido linoléico e ácido linolênico, além de seu custo mais baixo, é comumente padronizado em instituições hospitalares, sendo usado na prevenção e tratamento de lesões por pressão em pacientes acamados ${ }^{11}$.

Sendo assim, este estudo justifica-se, visto que uma pele com pouca hidratação fica mais suscetível à se romper e desenvolver lesões, entretanto, a partir da realização de um trabalho preventivo essas lesões podem ser evitadas. Hoje, no mercado, dispomos de vários produtos que objetivam hidratar a pele e prevenir lesões, porém questiona-se o efeito tópico destes óleos na pele, uma vez que existem poucos estudos que elucidem melhor a avaliação da eficácia destas formulações.

Entre as formas disponíveis que existem para a avaliação de produtos dermocosméticos, as metodologias in vivo não invasivas vêm sendo altamente usadas na realização dos estudos de eficácia durante o desenvolvimento de uma formulação cosmética ${ }^{8}$. Dentre elas, a biometria cutânea é mais precisa em relação com a análise dos efeitos dos produtos avaliados pelos próprios consumidores, ou seja, por análise clínica meramente visual ${ }^{9}$.

Concomitante a isto, a enfermagem por muitos anos tem buscado compreender o processo de prevenção e tratamento de feridas, pesquisando sobre fatores que favorecem a manutenção da integridade da pele e sua 
cicatrização, desenvolvendo uma gama de tecnologias que visam à cura destas lesões ${ }^{12}$. Desta forma, o enfermeiro deve estar em constante procura de outras opções terapêuticas, numa conduta multidisciplinar, valorizando seu cuidado, atuando com o objetivo de aplicar e avaliar tratamentos alternativos que agreguem baixo custo e ausência de efeitos colaterais ${ }^{13}$.

Diante dos aspectos já citados anteriormente o objetivo deste estudo foi investigar o efeito da aplicação tópica dos óleos de Chia, Girassol e Canola, por meio de biometria cutânea, mensurando a hidratação, PTEA, oleosidade e eritema.

\section{MÉTODO}

A pesquisa foi do tipo experimental ${ }^{14}$, a amostra foi composta por 44 voluntários, porém, o estudo iniciou com 45 voluntários havendo desistência de um (1) participante sem justificativa do abandono. As atividades experimentais deste estudo foram desenvolvidas no Laboratório de Nanotecnologia do Centro Universitário Franciscano em Santa Maria/RS, no período de setembro a outubro de 2016, nos turnos da manhã e tarde, com data e horário previamente agendados, conforme a disponibilidade dos voluntários.

O convite para participação da pesquisa foi divulgado em redes sociais e verbalmente nos locais de convivência acadêmica, e os voluntários que tiveram interesse foram convidados à comparecer ao Centro Universitário Franciscano.

Após a divulgação do convite, foram oportunizados dois encontros em dias e turnos diferentes, facilitando e proporcionando aos participantes a escolha do dia e horário que participariam, objetivando esclarecimentos sobre o estudo.

Neste primeiro contato foi explicada a importância do estudo, a necessidade do comprometimento e responsabilidade de cada um nesta pesquisa. Após concordarem com a pesquisa, assinaram o Termo de Consentimento Livre e Esclarecido, onde também foi entregue o protocolo de orientações e esclarecimento de uso dos produtos.

Foram incluídos na pesquisa voluntários maiores de 18 anos, sem história de reação a produtos tópicos e com a pele do cotovelo íntegra. Foram excluídos da pesquisa os voluntários que apresentaram históricos ou sinais de patologias dermatológicas, hipersensibilidade à algum componente da formulação, que apresentaram sinais de irritação ou dermatite de contato associado a produtos oleosos, gestantes ou mulheres que estivessem amamentando. Foi esclarecido ainda que qualquer intercorrência que pudesse ocorrer aos sujeitos do estudo, estes receberiam atendimento médico.

A área corporal escolhida para as avaliações por biometria cutânea foi o cotovelo, por ser uma área do corpo onde a pele é geralmente áspera e desidratada ${ }^{15}$. Inicialmente, os voluntários foram orientados a não utilizar nenhum produto cosmético na região dos antebraços principalmente na região do cotovelo três (3) dias antes do estudo, e durante a pesquisa somente os produtos oferecidos pelas pesquisadoras.

Os voluntários foram orientados a usar no cotovelo direito o creme hidratante neutro da marca Johnson ${ }^{\circledR}$; enquanto que no cotovelo esquerdo foram aplicados os óleos da marca Pazze ${ }^{\circledR}$, identificados pelas letras A (Chia), $B$ (Girassol) e C (Canola). Os voluntários foram distribuídos conforme a ordem de chegada, aos grupos A, B e C, sem o conhecimento de qual óleo usariam para não interferir nos resultados.

Os testes foram realizados segundo o método de caso-controle, onde cada indivíduo é controle de si mesmo. Estes estudos foram realizados no laboratório, em ambiente climatizado e monitorado com temperatura variando entre $22^{\circ} \mathrm{C}$ e $25^{\circ} \mathrm{C}$, e umidade relativa do ar entre $40-50 \%$. A fim de evitar erros durante a aplicação, os voluntários foram instruídos adequadamente em termos de quantidade e modo de uso de cada formulação, segundo especificado no protocolo. Os voluntários foram orientados à usar três (3) gotas de óleo uma vez ao dia no turno da noite no cotovelo esquerdo, e no cotovelo direito utilizaram a medida equivalente a um grão de ervilha do creme hidratante. As medidas de biometria cutânea foram realizadas antes do início da aplicação das formulações (medidas basais = dia 0), sendo este tempo, portanto, correspondente aos valores para o controle do ensaio. Posteriormente, as leituras foram realizadas no $7^{\circ}, 14^{\circ}$, $21^{\circ}$ e $28^{\circ}$ dia.

Para a coleta dos parâmetros, os voluntários permaneceram na posição ortostática com o antebraço totalmente relaxado, facilitando o manuseio do pesquisador. Foram efetuadas medidas em pontos diferentes do cotovelo dos mesmos, partindo de uma distância de $3 \mathrm{~cm}$ do cotovelo, utilizando como parâmetro um molde circular.

No estudo da biometria cutânea, avaliou-se o efeito da aplicação dos óleos de Chia, Girassol e Canola no cotovelo de indivíduos com pele saudável, por meio de equipamentos que oferecem informações relativas e permitem que vários parâmetros sejam analisados e avaliados como, por exemplo: conteúdo aquoso do estrato córneo (hidratação), pH da pele, coloração da pele, PTEA, dentre outros ${ }^{16}$. Neste estudo, para a avaliação dos parâmetros experimentais foram utilizados os seguintes aparelhos: Corneometer ${ }^{\circledR}, \quad$ Sebumeter ${ }^{\circledR}$, Tewameter ${ }^{\circledR}$ e Mexameter ${ }^{\circledR}$.

Para a determinação do conteúdo aquoso do estrato córneo (hidratação), o método da capacitância tem sido o mais utilizado através do uso do Corneometer ${ }^{\circledR}$ (CourageKhazaka Electronic, Alemanha), pois possui uma corrente de baixa frequência e é pouco afetado pela temperatura e umidade relativas. Este método é considerado concreto e reprodutível quando usado sobre condições padronizadas 
e corretas, sendo uma ferramenta de alta relevância para pesquisa cosmética, farmacológica e dermatológica ${ }^{16}$.

A oleosidade da pele, isto é, o índice lipídico, é calculado pela quantidade de sebo na pele. A medida do lipídeo é baseada na fotometria da gordura da área em questão, sendo que o método mais utilizado atualmente para análise da fracção lipídica da superfície cutânea designa-se por Sebumeter ${ }^{\circledR}$ (Courage-Khazaka Electronic, Alemanha). Este equipamento é constituído por um fotômetro capaz de medir o nível de transmissão de luz, através de uma fita de plástico opaca, especialmente concebida para o efeito, a qual torna-se progressivamente mais transparente à medida que absorve lípidos durante cerca de 30 segundos. 0 resultado é expresso em $\mu \mathrm{g} / \mathrm{cm}^{2}$ e representa a quantidade total de lípidos existente na superfície cutânea ${ }^{17}$.

O Tewameter ${ }^{\circledR}$ (Courage-Khazaka Electronic, Alemanha) é um equipamento baseado no princípio da difusão, de medida da PTEA em câmara aberta, que consiste numa sonda cilíndrica, aberta nas duas extremidades, ligada a um dispositivo de processamento de sinal, onde a sonda compreende dois pares de sensores, dois sensores de umidade emparelhados com dois sensores de temperatura ${ }^{17}$.

0 aparelho Mexameter ${ }^{\circledR}$ tem sido utilizado principalmente para a avaliação de produtos cosméticos, sendo descrito como um instrumento altamente discriminatório e sensível o suficiente para detectar possíveis pequenas diferenças na cor da pele, e também tem sido referido que a reprodutibilidade da sua medida é satisfatória ${ }^{18}$.

A pesquisa foi aprovada pelo Comitê de Ética em Pesquisa envolvendo seres humanos do Centro Universitário Franciscano/Plataforma Brasil, com parecer No: 1.432.250.

Para a análise dos resultados, utilizou-se a metodologia estatística dos dados incluindo a análise de variáveis como porcentagem, média e desvio padrão (DP).

\section{RESULTADOS}

\section{Avaliação do conteúdo aquoso do estrato córneo (grau de hidratação cutânea)}

Os resultados obtidos para a determinação da hidratação do estrato córneo no cotovelo esquerdo dos voluntários são expressos através da figura 1.

O valor de referência deve ser maior que $45 \mathrm{~g} / \mathrm{h} / \mathrm{m}^{2}$ para indivíduos saudáveis ${ }^{17}$, e neste estudo todos os óleos apresentaram uma melhora na hidratação cutânea, após 30 dias de aplicação. Pode-se observar que o óleo de chia aumentou em 38,2\% a hidratação do estrato córneo, enquanto que o óleo de girassol aumentou em 19,17\% e o óleo de canola em 9,26\% esta hidratação. Com isso, podemos concluir que o óleo que apresentou um maior indicativo de hidratação quando comparado aos demais foi o óleo A (óleo de chia).

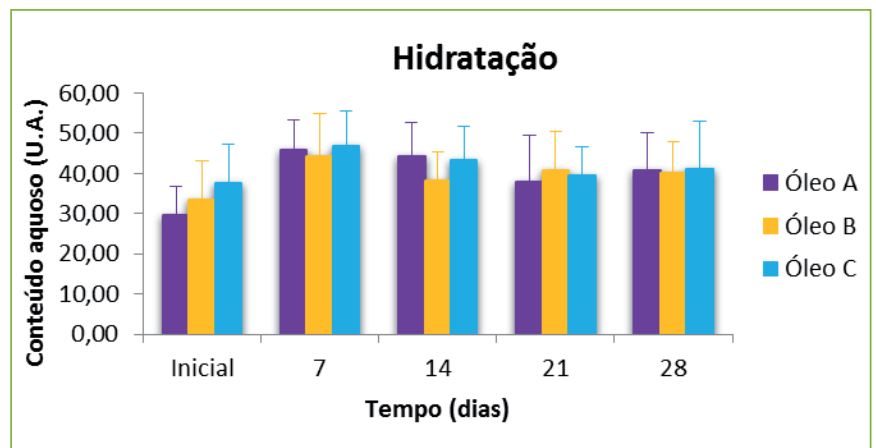

Figura 1: Comparação da hidratação inicial e após a aplicação dos óleos A: Chia; B: Girassol e C: Canola no cotovelo esquerdo dos participantes, sendo avaliados no início, aos 7, 14, 21 e 28 dias de tratamento; Santa Maria/RS.

Fonte: dados da pesquisa.

\section{Avaliação da perda transepidérmica de água (PTEA)}

A pele está sujeita a agentes externos e também à uma possível desidratação, na qual podem ser detectadas modificações sutis na integridade da barreira através da sua medição. $O$ aumento sucessivo da PTEA sugere que a função barreira da pele está danificada.

Neste estudo, comparando-se os resultados dos três (3) óleos pesquisados, podemos observar que o óleo que teve menor PTEA foi o óleo C (óleo de canola). Os resultados obtidos nesta pesquisa podem ser observados na figura 2.

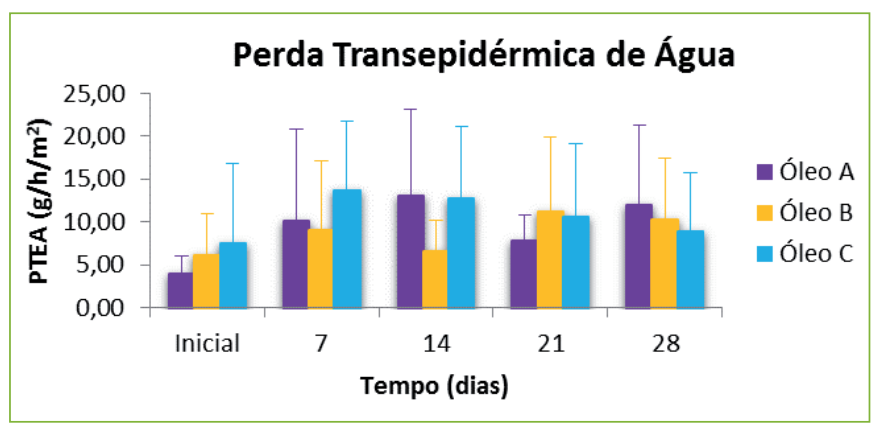

Figura 2: PTEA inicial e após a aplicação dos óleos de A: Chia B: Girassol e C: Canola no cotovelo esquerdo dos participantes, sendo avaliados em 0, 7, 14, 21 e 28 dias após a aplicação; Santa Maria/RS.

Fonte: dados da pesquisa.

Após os 28 dias, pode-se observar que o óleo de chia apresentou uma PTEA de $204 \%$, enquanto que para o óleo de girassol obtivemos $68,5 \%$ e para o óleo de canola $18,8 \%$. De acordo com estes resultados, podemos concluir que o óleo de canola apresentou menor índice de perda transepidérmica de água quando comparado aos outros óleos do estudo, enquanto que o óleo de chia exibiu maior percentual de PTEA.

\section{Avaliação da Oleosidade}

A figura 3 mostra o índice de oleosidade inicial e final, comparativo após a aplicação tópica dos óleos. 


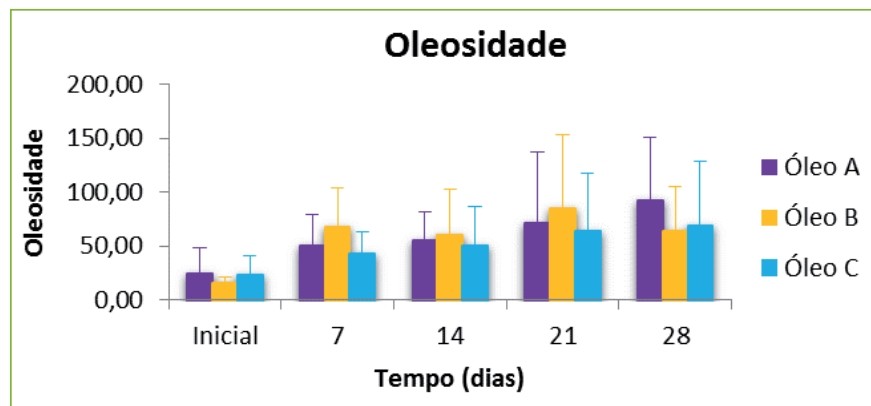

Figura 3: Comparação da oleosidade inicial e após a aplicação dos óleos de A: Chia B: Girassol e C: Canola no cotovelo esquerdo dos participantes, sendo avaliados no início, aos 7,14, 21 e 28 dias após a aplicação; Santa Maria/RS.

Fonte: dados da pesquisa.

Os resultados mostram que a pele do cotovelo dos voluntários apresentou um aumento da oleosidade, quando observados os valores inicial e final, conforme figura 3. Pode-se observar que o óleo de chia aumentou em $287,59 \%$ a oleosidade, enquanto que o óleo de girassol aumentou em $322,18 \%$ e o óleo de canola em $196,48 \%$. Com isso, conclui-se que os três (3) óleos testados aumentaram significativamente a oleosidade do cotovelo, destacando-se o óleo de Girassol.

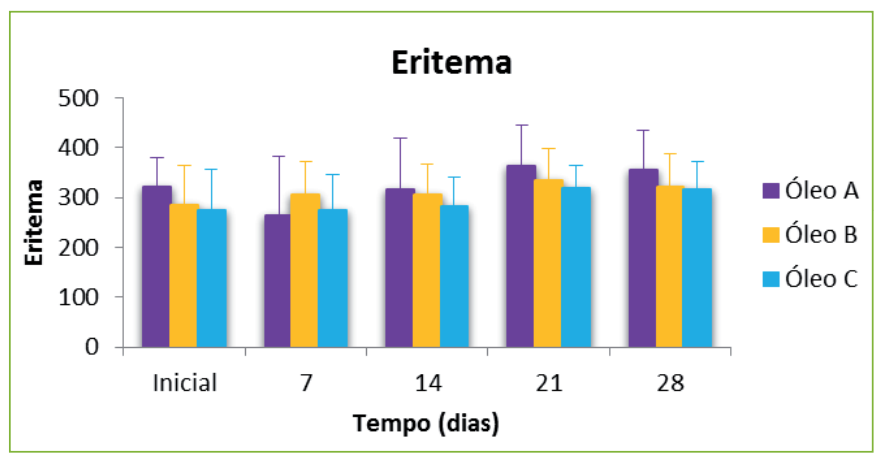

Figura 4: Comparação do eritema inicial e após a aplicação dos óleos de A: Chia B: Girassol e C: Canola no cotovelo esquerdo dos participantes, sendo avaliados no início, aos 7,14, 21 e 28 dias após a aplicação; Santa Maria/RS.

Fonte: dados da pesquisa.

Após os 28 dias, pode-se observar que o óleo de chia apresentou um índice de eritema de 9,51\%, enquanto que para o óleo de girassol obtivemos $11,93 \%$ e para o óleo de canola 13,90\%. Desta forma concluiu-se que o óleo que teve menor reação tecidual foi o óleo de chia em virtude de menor eritema ocasionado após sua aplicação, tornando-o menos agressivo em virtude de suas propriedades.

\section{DISCUSSÃO}

A hidratação representa o elemento mais importante para preservar a condição física e a aparência da pele. O equilíbrio do conteúdo aquoso no estrato córneo é indispensável para a manutenção da eudermia, ou seja, das condições normais da pele, que é uma das principais finalidades das formulações cosméticas ${ }^{17}$.

O estado de hidratação da pele é de grande importância dos pontos de vista dermatológico, cosmético e farmacêutico. Em cosmetologia, o nível de hidratação da pele, principalmente no estrato córneo, está diretamente relacionado com a sua aparência, enquanto que em dermatologia, a hidratação da pele é considerada como um indicador de seu estado de saúde ${ }^{16}$.

Neste estudo, todos os óleos pesquisados aumentaram a hidratação do cotovelo dos voluntários, porém, o óleo de chia apresentou o melhor resultado.

Ao uso de formulações tópicas contendo pantenol em diferentes concentrações $(0,5 \%, 1,0 \%$ e $5,0 \%)$ realizadas para a hidratação da pele, observou-se um aumento na hidratação, quando comparado aos valores inicias. Em todas as formulações contendo pantenol após 15 dias, porém apenas a formulação contendo $5 \%$ de pantenol aumentou a hidratação até o final dos 30 dias de estudo. Os experimentos foram realizados no antebraço de vinte voluntárias, entre 20 e 35 anos, durante 30 dias de aplicação ${ }^{17}$.

A PTEA é um método bem centrado para testar possível integridade do estrato córneo na pele do ser humano. A medida está relacionada com a função de barreira da pele, que exerce o controle sobre a perda de líquidos por transpiração e evaporação, influenciando na hidratação cutânea ${ }^{17}$.

Em recém-nascidos, utilizam-se óleos para proteger a pele para prevenir a PTEA, pois quanto mais oleosa a pele, menos liquido sai, sendo que o óleo atua como barreira cutânea ${ }^{11}$.

A integridade do estrato córneo é, provavelmente, o fator mais importante na resistência da pele a substâncias irritantes e sensibilizantes, e pode ser facilmente monitorada usando medidas da PTEA ${ }^{17}$.

Corroborando com a literatura, pode-se observar nos resultados, que o óleo de Canola apresentou menor índice de PTEA, no qual o próprio organismo equilibra a diferença entre a temperatura corporal e o ambiente por meio da evaporação de água.

Pesquisas com formulações contendo diferentes concentrações de extrato de Aloe vera liofilizado $(0,10 \%$, $0,25 \%$ e $0,50 \%$ ) foram realizados no antebraço de 20 voluntários do sexo feminino, durante um período de duas semanas. Os autores observaram que a PTEA basal não sofreu alteração quando comparada aos valores encontrados, após uma e duas semanas de análise, para todas as concentrações, indicando que a presença de Aloe vera nas formulações não alterou a função barreira da pele ${ }^{19}$.

A análise de uma formulação contendo glicerina, tocoferol e pantenol, foi realizada nos antebraços de 30 voluntários do sexo feminino, uma vez por semana, durante um período de três semanas, este estudo demonstrou que a formulação apresentou uma tendência a diminuir a PTEA após 1, 2 e 3 semanas de aplicação, sendo que as diferenças encontradas não foram significativas estatisticamente ${ }^{20}$. 
A oleosidade da pele serve para lubrificar o pelo, e também para formar um filme hidrolipídico juntamente com os produtos de excreção das glândulas sudoríparas. O filme hidrolipídico é uma camada oleosa fina que confere a característica de maciez à pele. 0 sebo cutâneo é também de grande relevância uma vez que impede a dessecação da superfície da pele e interfere no processo de permeação transepidérmica ${ }^{21}$.

Neste estudo, todos os óleos testados aumentaram a oleosidade do cotovelo, em especial o óleo de Girassol, que obteve a maior porcentagem em relação à medida inicial.

O eritema é considerado uma reação cutânea normal perante o sol, portanto, possibilita uma relação direta com os processos de possível irritação da pele através do uso de cosméticos, sendo por isso, frequentemente medido em testes para avaliação da segurança dos produtos. Nestes episódios, os vasos superficiais da derme são dilatados, causando um afluxo relevante de sangue e logo tendo um rubor momentâneo da pele ${ }^{16}$.

O crescente uso de cosméticos tem contribuído para um aumento alarmante na incidência de dermatite desenvolvida por este tipo de produto. As reações cutâneas têm sido observadas mais frequentemente na face, no antebraço e na axila, constituindo em torno de $10 \%$ da incidência deste tipo de reação ${ }^{16}$.

Estudos com formulações contendo vitamina A $(0,6 \%)$ C (2\%), E (2\%) e seus derivados (acetato, palmitato), suplementada com uma combinação de filtro UV, foram feitos no dorso de camundongos sem pelo, no qual o índice de eritema foi medido. A formulação contendo vitaminas A, C e E e um filtro UV fotoinstável (metoxicinamato de octila) não provocou qualquer irritação, e a formulação contendo vitaminas A, C e E e um filtro UV fotoestável (benzofenona-3) também não provocou irritação, uma vez que os valores obtidos para estas formulações não foram estatisticamente diferentes. No entanto a formulação que continha apenas vitaminas provocou uma irritação com um aumento no índice de eritema. Este estudo afirma que o filtro solar poderá contribuir não só no sentido de evitar a formação de eritema decorrente da ação da radiação, mas também diminuir o eritema provocado por outras substâncias em decorrência de uma possível fotodegradação destes componentes ${ }^{22}$.

O óleo que teve menor reação tecidual foi o óleo de chia, quando comparado aos outros óleos testados, porém, convém observar que, de um modo geral, a porcentagem de aumento do eritema foi pequena (9,51 a 13,90\%) nos três óleos estudados, confirmando os efeitos benéficos do uso tópico de AGE.

\section{CONCLUSÃO}

O principal propósito deste trabalho foi analisar a ação dos ácidos graxos essenciais em pele sadia por biometria cutânea, por meio de pesquisa experimental, com intuito de trazer conhecimento e resultados para melhorar a hidratação da pele e prevenir lesões.
Observou-se que o óleo com maior efetividade nas avaliações de hidratação e menor formação de eritema foi o óleo de chia. Em contrapartida, o óleo de Girassol teve o maior aumento na manutenção da oleosidade da pele e na avaliação da PTEA, o óleo de Canola apresentou maior manutenção de água no extrato córneo.

Logo, conclui-se que este estudo foi inovador e de grande relevância uma vez que comprova a eficácia do óleo de chia para a hidratação e diminuição do eritema da pele, prevenindo dano tissular. Espera-se que este estudo contribua para que novas pesquisas com evidências científicas sejam realizadas para melhorar o cuidado em feridas.

\section{REFERÊNCIAS}

1. Manhezi AC, Bachion MM, Pereira AL. Utilização de ácidos graxos essenciais no tratamento de feridas. Rev. bras. enferm. [Internet]. 2008 [citado em 30 mar 2017] ; 61(5 ): 620-628. Disponível em: http://www.scielo.br/scielo.php?script=sci_ arttext \&pid=S0034-71672008000500015\&lng=en. http:// dx.doi.org/10.1590/S0034-71672008000500015.

2. Quege GE, Bachion MM, Lino Junior RS, Lima ABM, Ferreira PS, Santos QR, Pimenta FC. Comparação da atividade de ácidos graxos essenciais e biomembrana na microbiota de feridas crônicas infectadas. Rev. Eletr. Enf. [Internet]. 2008 [acesso em 10 mar 2016]; 10(4):890-905. Disponível em: http://www.fen.ufg.br/revista/v10/n4/v10n4a02.htm.

3. Declair V. Tratamento de úlceras crônicas de difícil cicatrização com ácido linoleico. Jornal Brasileiro de Medicina. 2002; 82 (6):36-41.

4. Cavazana WC et al. Açúcar (sacarose) e triglicerídeos de cadeia média com ácidos graxos essenciais no tratamento de feridas cutâneas: estudo experimental em ratos. An. Bras. Dermatol. Rio de Janeiro) [Internet]. 2009 [acesso em 23 nov 2016]; 84(3):229-236. Disponível em: <http:// www.scielo.br/scielo.php?script=sci_arttext \&pid=S0365$05962009000300003 \&$ lng=en \&nrm=iso>.

5. Mota $D$ et al. Evidências na utilização dos ácidos graxos essenciais no tratamento de feridas. Ciências Biológicas e de Saúde Unit (Aracaju) [Internet]. 2015 [acesso em 23 nov 2016]; 2(3): 55-64.| Disponível em:https://periodicos.set.edu. br/index.php/cadernobiologicas/article/view/1948/1186

6. Coates W, Ayerza R. Production Potential of Chia in Northwestern Argentina. Indutrial Crops and Products. 2005; 5(3): 229-233. http://dx.doi.org/10.1016/09266690(96)89454-4.

7. Jeong SK et al. Effectiveness of Topical Chia Seed Oil on Pruritus of End-stage Renal Disease (ESRD) Patients and Healthy Volunteers. Ann Dermatol.2010;22(2):143-8.

8. Marques SR et al. Efeitos da aplicação tópica de óleo de semente de girassol em feridas cutâneas, em carneiros. Acta Cir. Bras. [Internet]. 2004 [acesso em 13 dez 2016]; 19(3):196209. Disponível em: http://dx.doi.org/10.1590/S010286502004000300005.

9. Ferreira $A M$ et al. Utilização dos ácidos graxos no tratamento de feridas: uma revisão integrativa da literatura nacional. Rev. esc. enferm.(São Paulo) [Internet]. 2012 [acesso 23 nov 2016];46(3):752-760. Disponível em: http:// 
www.scielo.br/scielo.php?script=sci_arttext $\&$ pid $=$ S008062342012000300030 \&lng=en \&nrm=iso.

10. Hatanaka E, Curi R. Os ácidos graxos e cicatrização de feridas: uma revisão. Revista Brasileira de Farmacologia [Internet]. 2007 [acesso em 28 ago 2015]; 88(2):53-8. Disponível em: http://rbfarma.org.br/files/PAG53a58_ACIDOSGRAXOS.pdf.

11. Fernandes LM, Braz E. A utilização do óleo de girassol na prevenção de úlceras de pressão em pacientes críticos. Nursing (São Paulo). 2002; 5(44): 29-34.

12. Dochterman JM, Bulechek GM. Classificação das intervenções de Enfermagem (NIC). 4a ed. Porto Alegre: Artmed; 2008.

13. Silva JC, Santos RFEP, Caffaro KMT, Veríssimo RCSS, Bernardo THL, Araújo Jr JX, Campesatto EA, Bastos MLA. Avaliação da atividade antimicrobiana de Tabebuia roseo-alba (Ridl.) Sand (Ipê branco). In Derme. 2014; 68(6): 8-11.

14. Gil AC. Como elaborar projetos de pesquisa. 4. ed. São Paulo: Atlas; 2008.

15. Dangelo JG, Fattini CA. Anatomia humana sistêmica e segmentar. 2a ed. São Paulo: Atheneu; 2006.

16. 16. Silva APT. Biometria cutânea com formulações semissólidas contendo nanocápsulas de palmitato de ascorbila [dissertação]. Santa Maria (RS): Centro Universitário Franciscano;2012. Disponivel em: http://sites. unifra.br/ Portals/11/Disserta\%C3\%A7\%C3\% B5es/2012-1/ Disserta\%C3\%A7\%C3\%A30\%20final\%20Ana\%20Paula.pdf

17. Camargo Jr FB. Desenvolvimento de formulações cosméticas contendo pantenol e avaliação dos seus efeitos hidratantes na pele humana por bioengenharia cutânea. Dissertação (Mestrado em Ciências Farmacêuticas) - Curso de PósGraduação em Ciências Farmacêuticas, Faculdade de Ciências Farmacêuticas de Ribeirão Preto. São Paulo, SP; 2006.

18. Park ES et al. Application of a pigment measuring device - Mexameter - for the differential diagnosis of vitiligo and nevus depigmentosus. Skin Research and Technology. 2006;2(4):298-302.

19. Dal'Belo SE, Gaspar LR, Maia Campos PMBG. Moisturizing effect of cosmetic formulations containing Aloe Vera extract in different concentrations assessed by skin bioengineering techniques. Skin Research and Technology. 2006; 12:241-246.

20. Cheng Y, Dong Y, Wang C, Schrader A. Protection effect of cosmetics on human skin under simulated rigorous environment. Skin Research and Technology. 2008; 14:45-52.

21. Cunha AP et al. Tipos de pele e cuidados gerais a ter em conta na sua manutenção. In: Cunha, et al. (Eds.). Plantas e produtos vegetais em cosmética e dermatologia. Lisboa: Fundação Calouste Gulbenkian; 2004. p. 33-42.

22. Gaspar LR, Maia Campos PMBG. Photostability and efficacy studies of topical formulations containing UV-filters combination and vitamins A, C and E. International Journal of Pharmaceutics. 2007; 343:181-189. 